\title{
Research on Math Anxiety of Elementary School Teachers
}

\author{
Mengchong Chen
}

\author{
School of Social Science \\ University of California, Irvine, 92697, USA. \\ Corresponding author. Email:mengchoc@uci.edu
}

\begin{abstract}
Mathematics anxiety refers to the negative emotional reactions such as anxiety, tension, uneasiness and fear, and even physiological manifestations, such as sweating, rapid heartbeat and so on. Mathematics anxiety may lead mathematics learners to avoid mathematics learning, resulting in the reduction of academic achievements. Not only students, but also math teachers show the symptoms of math anxiety. Existing studies have proved that mathematics anxiety exists in many groups of teachers. Therefore, this paper focuses on the causes and influencing factors of primary school teachers' mathematics anxiety, analyzes the coping styles, and puts forward some suggestions for future research direction.
\end{abstract}

Keywords: Mathematics Anxiety, Negative Experience, Mathematics Teaching, Teaching Methods

\section{INTRODUCTION}

In recent years, people pay more attention to their own psychological state and more terms related to psychology enter people's vision, which also improves the awareness of mathematical anxiety. In fact, long before that, perhaps when mathematics was born, the anxiety accompanying it has existed. Many people around the world are distressed by this, and China is no exception. Since 1990, more in-depth research on mathematics anxiety has been carried out in China. However, in recent years, the domestic research on mathematics anxiety has focused on exploring the influencing factors of students' mathematics anxiety, and the literature reviewand research on teachers' mathematics anxiety are few. Among them, the existing research mainly focuses on the anxiety of pre-service mathematics teachers and technical school mathematics teachers, and its content mainly includes the analysis of the causes of anxiety $[1,2]$. However, the prediction of pre-service teachers' mathematics anxiety to elementary school teachers' mathematics anxiety has not been clearly tested, so it can not represent the primary school mathematics teachers' group. Moreover, the categories of anxiety and mathematics anxiety are inconsistent, which can not accurately explain and predict the causes of mathematics anxiety of primary school teachers. As we all know, mathematics knowledge, as a main course, occupies a large proportion in the curriculum. Therefore, primary school teachers' mathematics anxiety and their attitude and cognition towards mathematics have a certain impact on primary school students' mathematics learning. All teachers used to be students. Mathematics teachers who grow up in an anxious learning environment may associate bad experiences about mathematics with mathematics learning, and their students may also be affected by it. Thus, it forms an adverse cycle. On the bright side, teachers with math anxiety may also use their ability to perceive anxiety to experience and alleviate students' math anxiety. In order to solve the anxiety problem, the best way is to stop it from the source. This requires teachers to understand how mathematics anxiety is produced, and find the best solution of their own according to the factors affecting it.

\section{THE CAUSES AND CURRENT SITUATION OF MATH ANXIETY}

So far, many scholars have defined mathematics anxiety. Mathematics anxiety is regarded as an obstacle to learning mathematics. Patients may experience a psychological state of fear when doing mathematics problems, thus affecting their mathematics performance [3]. People with math anxiety will feel uncomfortable or nervous when thinking or doing math problems, and 
even forget and lose self-confidence [4]. Richardson and Suinn believe that mathematics anxiety includes tension and anxiety that interfere with mathematics operation and mathematical problem solving in various daily life and academic environments [5]. Mathematics anxiety has many manifestations, and it is not only emotional anxiety, like tension, anxiety, fear and other negative emotional reactions, but also physiological manifestations, such as sweating, rapid heartbeat and other changes [6]. Math anxiety may cause math learners to avoid math learning, such as fewer math classes than their peers and spend less time on math learning [7]. It can be seen that although scholars have not reached a consensus on a certain definition, mathematics anxiety is recognized as an uncomfortable experience in mathematics learning, and affects learners' mathematics learning behavior to varying degrees.

\subsection{Causes of Teachers' Math Anxiety}

The causes of mathematics anxiety have been widely studied. At present, scholars mainly summarize three reasons: negative experience related to mathematics; the incomprehensible nature of mathematics; differences in the degree of anxiety between genders. Tobias' research found that when students feel that their learning is out of control or embarrassing in front of their peers, or have significant negative experiences with mathematics teachers, they will associate negative emotions with mathematics learning [4]. However, every teacher used to be a student. If students with the above experience become teachers, they are likely to teach with negative emotions about mathematics, forming a vicious circle. Mason found that factors related to the essence of mathematics, such as many rules that mathematics needs to remember, the abstract characteristics of mathematics, and difficult exercises in mathematical problem solving, may lead to mathematical anxiety [8]. In addition, gender can also affect the degree of teachers' mathematical anxiety. Many studies have shown that among teachers, women have a higher and more common degree of mathematics anxiety than men, and the vast majority of teachers are women. According to the stereotype threat theory, the social stereotype of women's mathematical ability [3], women may worry about being judged and treated according to this concept, resulting in a sense of threat, which is also one of the incentives for women's higher mathematical anxiety than men.

To be sure, mathematics anxiety is also related to China's educational model. Huang Xiaorui found that Chinese students have more math homework than foreign students and take longer to complete according to Pisa 2012 data analysis, [9]. Based on Pisa's system level association between mathematics performance and mathematical anxiety table [2], students in Shanghai, Macao and Hong Kong have higher mathematics anxiety, which is much higher than that in Britain, the United States and Switzerland. Therefore, mathematics anxiety in China needs to be paid more attention. It is tough for mathematics teachers trained in this high anxiety environment not to be affected by it.

\subsection{Math Maladjustment and Math Anxiety Felt by Teachers}

Pre-service primary school teachers often become real teachers in the future. The research of a Chinese scholar Kong Yehan mentioned the similarity and correlation between statistical anxiety and mathematical anxiety, and measured the Statistical Anxiety of preservice teachers. The results showed that among the preservice teachers, the proportion of subjects with high statistical anxiety is low, and the overall anxiety level of subjects is in a moderate state. According to the inverted U-shaped system proposed by Yerks Dodson, the author infers that one-third of Chinese pre-service teachers have statistical obstacles [10]. However, it is worth considering that the direct relationship between statistical anxiety and mathematical anxiety. In foreign studies, Ball found that in a group of pre-service primary school teachers, more than one third said they were not good at mathematics and tended to avoid mathematics. Burton found that $52 \%$ of pre-service primary school teacher participants had a negative view of mathematics, while only $14 \%$ had a positive view [11]. Hembree discovered the math anxiety level of preservice teachers is higher than that of senior students [12]. Colleen's study found that junior primary school students have a higher math anxiety level than senior primary school teachers (teachers with high math anxiety have a lower understanding of math knowledge); the mathematics anxiety of teachers with a mathematics qualification certificate is lower than that of teachers without a mathematics qualification certificate; teachers with high mathematics anxiety tend to adopt more traditional methods for Mathematics Teaching [6].

\section{THREE FACTORS AFFECTING TEACHERS' MATH ANXIETY}

\subsection{External locus of control / negative experiences related to mathematics}

In a study, most participants with math anxiety expressed discomfort related to math learning in their school career. For example, a participant named Beth can still vividly recall the sharp criticism of her math teacher in public and her feelings at that time after decades [13]. It can be seen that the negative experience has a profound and even indelible impact on students' mathematics learning. These experiences may lead to aversion to mathematics and lead to anxiety and other symptoms. 


\subsection{Teacher's mathematics skills}

Spatial ability is the basis of learning mathematics. A series of studies show that teachers with higher mathematical anxiety have lower spatial ability. It can be seen that lack of mastery of mathematics related abilities will lead to anxiety. In addition, the lack of teaching related ability or experience may also lead to mathematics anxiety. Due to the reserve of teaching experience is beyond the control of teachers, although many teachers know how to solve mathematical problems, they have not found the simplest and understandable way for students. Some teachers show that when students cannot understand the solution to the problem, teachers with mathematics anxiety often find it difficult to express and teach students in another way. The results of another study show that previous teaching experience accounts for the vast majority of teachers' anxiety, followed by children's understanding and adaptation to the established teaching structure [14]. When teachers cannot master factors other than mathematics knowledge: classroom management, supervision institutions, resources, such as the control of time, they may feel anxious. This is actually due to their lack of adaptability to teaching.

\subsection{Selection of teaching methods}

Teachers with high mathematics anxiety tend to adopt traditional teaching style [15], and they also believe in mathematics concepts consistent with the mainstream beliefs in the United States [6]. In this mathematical concept, teachers are considered not to admit that their mathematical ability or knowledge reserve is insufficient or uncertain [16]. This belief requires teachers to show a state of "always being confident in mathematics and never making mistakes". In fact, no one is perfect and everyone will make mistakes. This unrealistic concept and pursuit may cause or aggravate teachers' mathematics anxiety. In addition, the traditional classroom often emphasizes training, regular examination and memory. Teachers with mathematics anxiety tend to adopt a fixed mathematics teaching plan, adhere to the preparation of textbooks, solve the problems of words first, and then deal with the problems related to words [17]. However, in case of emergencies, such as school exercises disrupt the teachers' teaching progress that results in incomplete classroom content, teachers who adopt teaching methods may feel anxious for less controlling over the curriculum. If teachers choose flexible teaching methods by allowing students to preview the remaining contents independently, and carry out discussion links at the beginning of the next class, such as setting relevant topics for students to group, then requiring students to complete and report the solution process through communication. It is likely to help students increase their understanding and memory of knowledge points, and teachers will maintain control over the classroom in this process.

\section{THE INFLUENCE OF TEACHERS' MATHEMATIC TEACHING BEHAVIOR AND MATHEMATIC ANXIETY ON STUDENTS}

\subsection{Negative Influence}

In the face of teachers' mathematics anxiety, the students are most directly affected. So far, the number of teachers' mathematical anxiety in China's academic research is very few, and there is almost no research on primary school teachers' mathematical anxiety. Relevant research on mathematics teaching behavior shows that teachers' attitude towards students' achievement and teachers' support has an impact on students' mathematics anxiety. According to the investigation on the current situation of students in the lower grades $\left(1^{\text {st }}\right.$ to $3^{\text {rd }}$ grade) of primary school, if teachers show a disappointed response to pupils' mathematics performance in learning, it will directly affect the generation of pupils' mathematics anxiety. Moreover, the proportion of mathematics anxiety of students in $3^{\text {rd }}$ grade of primary school is higher than that of students in lower grades, which is due to their academic pressure and the enhancement of Mathematics Education [18]. Jiawang's research shows that teacher support has an obvious negative predictive effect on mathematics anxiety of second graders in primary school. In contrast, many studies abroad have confirmed that teachers' high mathematics anxiety will lead to students' low mathematics performance. The influence of primary school teachers' mathematics anxiety on primary school students' mathematics anxiety needs to be continued. Monica studied the relationship between teachers and mathematics anxiety of children aged $1^{\text {st }}$ to $3^{\text {rd }}$ grades in primary school. The results show that there is no observable relationship between teachers' mathematics anxiety and students' mathematics anxiety [8]. However, this study did not provide a conclusive basis, nor did teachers' mathematics anxiety generally predict students' mathematics anxiety. We could see from it that teachers' mathematical anxiety may not be closely related to students' mathematical anxiety, but it has an impact to a certain extent.

\subsection{Positive Influence}

In addition, the mathematics anxiety of primary school teachers may have a positive impact on students. Some teachers who have experienced math anxiety say they can sympathize with and experience children with math problems. Most teachers with math anxiety can recognize their math anxiety, and some of them are determined to break the vicious circle of stimulating students' unpleasant math experience due to their math 
anxiety [11]. This is the unique advantage of teachers with math anxiety. Because of their own experience, teachers with mathematics anxiety can better understand the source of mathematics anxiety, the relationship between mathematics anxiety and mathematics achievement, and the impact on mathematics thinking ability. Therefore, they have a strong sense of responsibility to help students with math anxiety and are better at identifying students' math anxiety, which is a favorable factor for them to teach math than other teachers. In the long run, students' confidence in mathematics learning will be obtained and maintained, and teachers with mathematics anxiety will get a sense of achievement and gain happiness. In the long run, teachers' mathematics anxiety will be reduced, and students' and teachers' mathematics self-efficacy will be improved, forming a positive cycle.

\section{SUGGESTIONS ON PREVENTING AND ALLEVIATING MATH ANXIETY}

\subsection{Suggestions for elementary school math teachers}

(1). Admit the difficulty of mathematics learning, rather than question your mathematics ability. Mathematics is recognized as one of the most difficult subjects in the world. Understanding the characteristics of mathematics learning will help teachers accept the learning and teaching of mathematics. At the same time, in an interview with a former primary school teacher, a participant named Beth mentioned that when her primary school mathematics teacher admitted the difficulties in mathematics learning and advocated students to forget their ideas about mathematics, Beth accepted mathematics learning from the bottom of her heart [11]. It can be seen that when the teacher honestly expressed her feelings about mathematics learning, students are likely to be sympathetic to the teacher, Realize that this is the difficulty of mathematics, so as to weaken the individual's anxiety about mathematics.

(2). Ensure basic skills and strengthen the handling of mathematical problems. Teachers' mastery of the basic knowledge of mathematics teaching, such as strengthening the ability of logical reasoning and understanding of abstract geometry, will help to establish their self-confidence in mathematics learning.

(3). Increase the experience of mathematics teaching. Teachers can enhance their understanding of the teaching process by observing other teachers. Studies have shown that pre service teachers can help alleviate their math anxiety by observing interns. This helps them to understand the teaching methods and contents, students' mathematical habits in the classroom and strategies to deal with the classroom [13]. In addition, teachers can constantly optimize mathematics teaching and enhance their confidence in teaching through regular self reflection.

\subsection{Suggestions for teaching students}

The central content of alleviating and alleviating students' mathematics anxiety is to establish a good link with students, and make students feel warm and sufficient sense of security in the process of mathematics learning through positive expression and interaction, so as to create a healthy mathematics learning environment.

(1). Help students feel better, rather than passing the information that mathematics is difficult and students are not good at mathematics. Through positive encouragement, stimulate students' confidence in their mathematics learning. This requires teachers to emphasize the importance of working hard in mathematics learning and guide students to realize that mistakes are a part of successful learning. For example, when students encounter math problems, teachers can say: "yes, this work is very challenging, but I know you can do it through hard work" [19].

(2). Adopt teaching methods and deal with specific problems in different ways. Teachers can teach mathematics in a more flexible way, pay attention to the applicability of teaching to most students, combine mathematical problems with life scenes, and improve students' interest in mathematics [5]. Teachers can also change the scoring mode of mathematics curriculum and replace a large exam that needs long-term study and review with several small exams in different learning periods, so as to reduce students' mathematics learning pressure. Teachers need to express their support for critical thinking, encourage students to explore and think independently, and find a variety of solutions.

(3). Reduce the emphasis on correct answers and calculation speed [7]. When correcting homework and tests, teachers should pay more attention to students calculation process rather than results, so as to help students better understand the mistakes and realize that they have the ability to calculate the correct answers through the correction process.

(4). Avoid embarrassing situations for students. Teachers should not force students with poor mathematical performance into the environment that frightens them, but should give them questions that can be answered within their ability according to their ability, so as to enhance students' mathematical selfconfidence $[7,20,21,22]$ So as to reduce students possible negative experience related to mathematics.

\section{CONCLUSION}

Mathematics anxiety is a negative emotion produced when carrying out mathematics related tasks. The 
negative experience related to mathematics, the obscure nature of mathematics and the influence of gender have been proved to be the possible causes of mathematics anxiety. In addition, the understanding of mathematics anxiety should be further analyzed according to the national conditions and education system of our country. At present, for primary school teachers, the factors affecting their mathematics anxiety focus more on themselves, which is mainly related to their own skills (including mathematics ability and teaching ability) and teaching methods. However, primary school teachers' mathematics anxiety does not always bring negative effects. Primary school teachers who have experienced mathematics anxiety can help find out in time and alleviate students' anxiety through appropriate methods. This also puts forward more requirements for future mathematics teachers: not only do they have knowledge reserve, teaching ability and experience accumulation, but also pay attention to their own and students' psychological state, honestly face the existing problems, seriously interact with students, and adopt the teaching method of encouragement, so as to guide students to have more interest in mathematics learning, cure their own math anxiety.

\section{REFERENCES}

[1] Lifeng Cai. Causes and Countermeasures of mathematics teachers' anxiety in technical schools.

[2] OECD. PISA. Assessment and Analytical Framework: Mathematics , Reading, Science , Problem Solving and Financial Literacy [M]. OECD, Paris, 2012.

[3] Beilock, S. L., Gunderson, E. A., Ramirez, G., \& Levine, S. C. Female teachers' math anxiety affects girls' math achievement. Proceedings of the National Academy of Sciences, vol. 107(5), 2010, pp. 1860-1863.

[4] Tobias, S. Math mental health: Going beyond math anxiety. College Teaching, vol. 39(3), 1991, pp. 91-93.

[5] Curtain-Phillips, M. The Causes and Prevention of Math Anxiety, 2001, DOI: http:// www.mathgoodies.com/articles/math_anxiety.html

[6] Colleen M. Ganley, Robert C. Schoen, Mark LaVenia, Amanda M. Tazaz. The Construct Validation of the Math Anxiety Scale for Teachers, 2019, DOI: https://journals.sagepub.com/doi/full/10.1177/2332 858419839702

[7] Files.eric.ed.gov. Strategies for Reducing Math Anxiety, 2011, DOI: https://files.eric.ed.gov/fulltext/ED536509.pdf
[8] Szczygieł, M. When does math anxiety in parents and teachers predict math anxiety and math achievement in elementary school children? The role of gender and grade year. Social Psychology of Education, vol. 23(4), 2020, pp. 1023-1054.

[9] Xiaorui, Huang. The Effects of School Homework and out of School Math Tutoring on Math Anxiety: A Comparison between Shanghai (China) and Finland, 2015.

[10] Yehan, Kong. Pre-service teacher's statistics anxiety's level and the influence, 2010.

[11] Harper, N. W., \& Daane, C. J. Causes and reduction of math anxiety in preservice elementary teachers. Action in Teacher Education, vol. 19(4), 1998, pp. 29-39.

[12] Hembree, R. The nature, effects, and relief of mathematics anxiety. Journal for Research in Mathematics Education, vol. 21(1), 1990, pp. 33 46. https://doi.org/10.2307/749455

[13] Brown, A., Westenskow, A., \& Moyer-Packenham, P. Teaching anxieties revealed: Pre-service elementary teachers' reflections on their mathematics teaching experiences. Teaching Education, vol. 23(4), 2012, pp. 365-385.

[14] Lovett, J. N., Dick, L. K., McCulloch, A. W., Sherman, M. F., \& Martin, K. Preservice mathematics teachers' professional noticing of students' mathematical thinking with technology. Journal of Computers in Mathematics and Science Teaching, vol. 38(4), 2019, pp. 305-319.

[15] Bandura, A. Perceived self-efficacy in cognitive development and functioning. Educational Psychologist, vol. 28(2), 1993, pp. 117-148. DOI: https://doi.org/10.1207/s15326985ep2802_3

[16] Givvin, K. B., Stipek, D. J., Salmon, J. M., \& MacGyvers, V. L. In the eyes of the beholder: Students' and teachers' judgments of students motivation. Teaching and Teacher Education, vol. 17(3), 2001, pp. 321-331. DOI: https://doi.org/10.1016/S0742-051X(00)00060-3

[17] Eysenck, M. W., Derakshan, N., Santos, R., \& Calvo, M. G. Anxiety and cognitive performance: attentional control theory. Emotion, vol. 7(2), 2007, 336.

[18] Tingting Liu. Investigation on the current situation of mathematics anxiety of early elementary school students and its Countermeasures, 2020.

[19] Aft.org. Math Anxiety: Can Teachers Help Students Rescue It? 2014, DOI: https://www.aft.org/sites/default/files/periodicals/b eilock.pdf 
[20] Ashcraft, M.H., \& Krause, J.A. Working Memory, Math Performance, and Math Anxiety. Psychonomic Bulletin \& Review, vol. 14(2), 2007, pp. 243-248.

[21] Haralson, K. Math Anxiety: Myth or Monster? Presentation at National Council of Teachers of Mathematics Central Regional Conference, Paducah, KY, 2002, DOI: http://apbrwww5.apsu.edu/haralsonk/ppt/anxiety presentation[paducah].ppt

[22] Woodard, T.The Effects of Math Anxiety on PostSecondary Development Students as Related to Achievement, Gender, and Age. ERIC Document Reproduction Service. vol. 9(1), 2004. 